\section{GDC ANNOUNCES ASTONISHING ARF INCREASES}

Dental news and social media platforms were in uproar on 30 June 2014 when the General Dental Council (GDC) announced that it plans to increase the annual retention fee (ARF) for dentists by $64 \%$.

\section{\#ARFhike}

The GDC plans to increase the ARF for dentists from $£ 576$ to $£ 945$, and for dental care professionals (DCPs) from $£ 120$ to $£ 128$. For DCPs, many of whom have protested the $£ 120$ fee, this represents a $6.7 \%$ increase.

The GDC has launched a consultation on the level of the fee, following a consultation focussing on the policy used when setting the fee. It says that it is increasing the fees in order to collect an extra $£ 18$ million to enable it to deal with the extra volume of complaints and fitness to practise hearings it anticipates in 2014 and 2015. Complaints have increased by $110 \%$ since 2011 , which the GDC says is the most expensive part of regulating the dental profession.

The British Dental Association (BDA) has slammed the proposal, calling it 'wholly unacceptable' and at odds with the actions of other regulators. Chair of the Principal Executive Committee, Mick Armstrong, said: 'The suggestion that the profession pay more to fund a Council that has been shown unable to do its job properly is frankly astonishing' and called for the GDC to investigate the underlying reasons for the increase in complaints about registrants.

For further information and to submit your views on the planned ARF price increases, visit http://www.gdc-uk.org/ GDCcalendar/Consultations/pages/ Consultation-on-the-Annual-Retention-Fee(ARF)-Level-for-2015.aspx. The consultation is open until 4 September 2014.

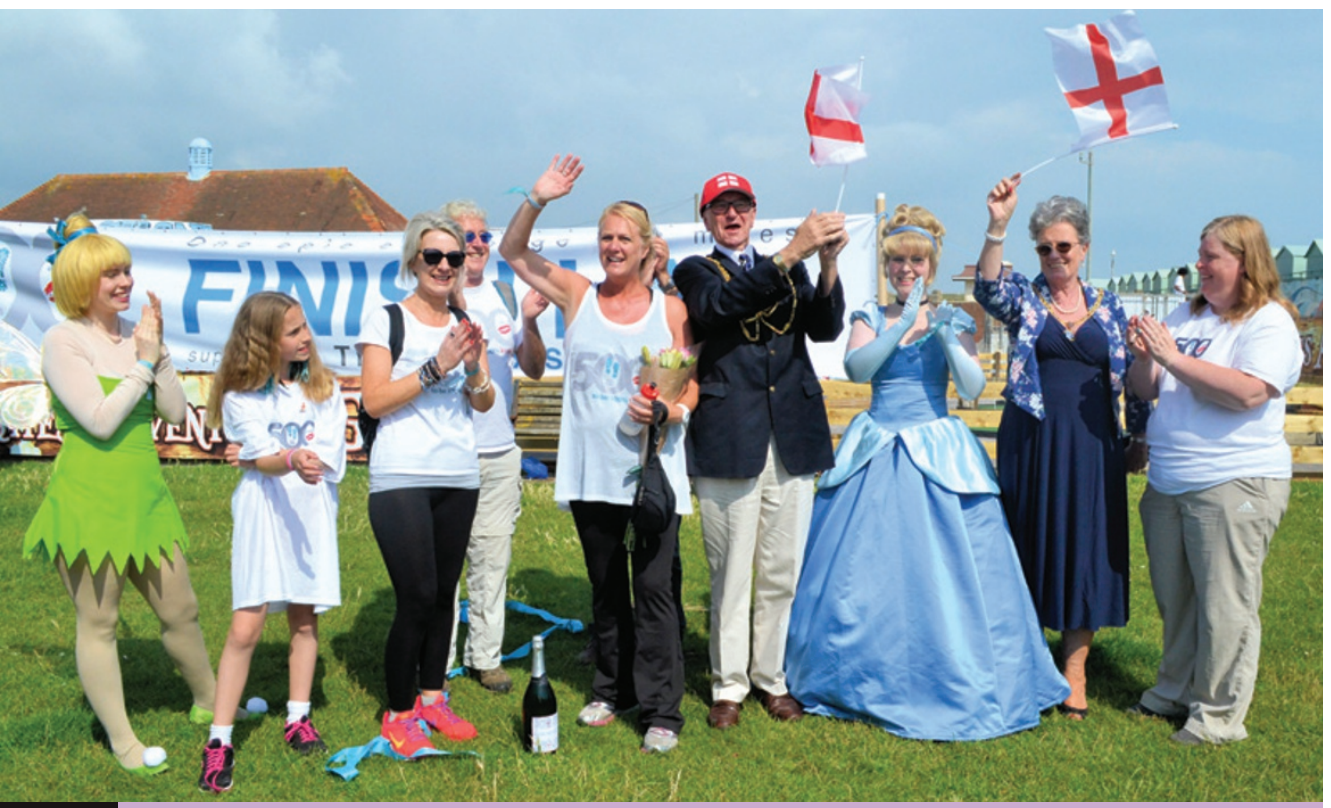

\title{
DENTAL HYGIENIST WALKS 500 MILES FOR MOUTH CANCER
}

Dental hygienist Christina Chatfield has raised almost $£ 20,000$ for Mouth Cancer Action by walking 500 miles across the UK.

Christina, who owns Dental Health Spa Brighton, finished her '500 Miles for Smiles' walk on 19 June in Brighton.

The walk began at Christina's first practice in Kirriemuir, Scotland, a month earlier, and took in some of the east coast's most attractive cities. More than 300 people joined the walk on various legs of the route.

Christina said: 'I spoke to a number of people along the route and very few are aware of the link between mouth cancer and the human papillomavirus (HPV), one of the key factors behind the increase. It was a gruelling month for me, but making those people I met aware of mouth cancer was worth it'.

In addition to donations going to Mouth Cancer Action, a long-standing campaign run by the British Dental Health Foundation, fellow dental charity Heart Your Smile also received a share of the fundraising.

\section{ADAM APPOINTS NEW PRESIDENT}

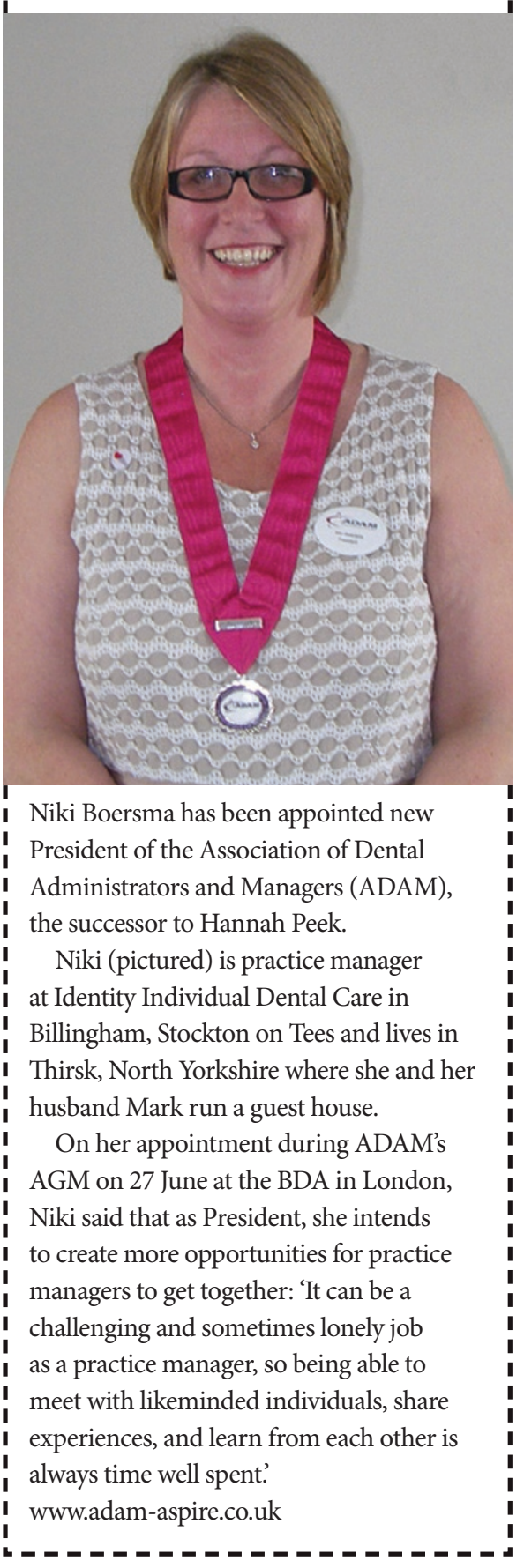

\section{BADN INVESTIGATES NEEDLESTICK INJURIES}

The British Association of Dental Nurses (BADN) is conducting a survey into the incidence of needlestick injuries among dental nurses working in the UK, on behalf of Initial Medical.

There are currently no statistics on dental nurse needlestick injuries. To take part in the survey, go to http://www.cvent.com/d/m-OP8TJA0aL8pXDWHXLWw/snxs/P2/3B. 